\title{
Scanning Electrochemical Microscopy (SECM) Study of the Electrochemical Behavior of Anodized AZ31B Magnesium Alloy in Simulated Body Fluid
}

\author{
Leandro Antonio de Oliveira ${ }^{a}$, Rejane Maria Pereira da Silva ${ }^{b}$, Renato Altobelli Antunes ${ }^{a * \mathbb{D}}$ \\ ${ }^{a}$ Centro de Engenharia, Modelagem e Ciências Sociais Aplicadas (CECS), \\ Universidade Federal do ABC (UFABC), Santo André, SP, Brasil \\ ${ }^{b}$ Instituto de Pesquisas Energéticas e Nucleares (IPEN), São Paulo, SP, Brasil
}

Received: January 29, 2019; Revised: July 26, 2019; Accepted: September 25, 2019

\begin{abstract}
In this work, scanning electrochemical microscopy (SECM) was employed to study the corrosion behavior of anodized AZ31B magnesium alloy exposed to simulated body fluid. SECM measurements were carried out in surface generation/tip collection mode. The hydrogen evolution flux caused during corrosion of the magnesium alloy was oxidized at the ultra-microelectrode (UME). Thus, this experimental procedure allowed evaluating the effect of the anodic protection in this alloy from the SECM analysis of Z- approximation curves, cyclic voltammograms and topographic maps. The results evidence differences in the local electrochemical response of magnesium alloy in the anodized and pristine conditions. The main sites of $\mathrm{H}_{2}$ evolution were verified in the magnesium alloy without anodizing at short exposure times.
\end{abstract}

Keywords: magnesium alloy, corrosion, anodizing, SECM.

\section{Introduction}

Magnesium alloys have recently gained increasing attraction as biodegradable and biocompatible materials for resorbable medical implants. However, one drawback of these alloys is that they present high degradation rates when are exposed to biological environments, being prone to localized corrosion ${ }^{1-7}$.

There are evidence that magnesium alloy corrosion process is initiated at heterogeneous sites in the microstructure which are mainly due to localized variations in the chemical composition of the alloy formed during the casting process ${ }^{8,9}$.

Several works showed that one of the simplest and most effective methods for studying the corrosion rates of magnesium in aqueous solutions is by measuring hydrogen gas evolution associated with the magnesium corrosion process as shown in Eq. (1) 1$)^{10-13}$.

$$
\mathrm{Mg}+2 \mathrm{H}_{2} \mathrm{O} \rightarrow \mathrm{Mg}^{2+}+\mathrm{H}_{2}+2 \mathrm{OH}^{-}
$$

According to it, for each $\mathrm{Mg}^{2+}$ ion produced from the corrosion of $\mathrm{Mg}$ metal, one molecule of $\mathrm{H}_{2}$ is evolved.

Normally, magnesium and its alloys produce magnesium hydroxide $\left(\mathrm{Mg}(\mathrm{OH})_{2}\right)$ and molecular hydrogen $\left(\mathrm{H}_{2}\right)$ when are exposed to aqueous environments, where the main cathodic reaction is water reduction, with hydrogen evolution and local alkalization, as shown in Eqs. (2) to (4) ${ }^{14,15}$.
Anodic reaction: $M g \rightarrow M g^{2+}+2 e^{-}$

Cathodic reaction: $2 \mathrm{H}_{2} \mathrm{O}+2 e^{-} \leftrightarrows 2 \mathrm{OH}^{-}+\mathrm{H}_{2}$

Overall reaction: $\mathrm{Mg}+2 \mathrm{H}_{2} \mathrm{O} \leftrightarrows \mathrm{Mg}(\mathrm{OH})_{2}+\mathrm{H}_{2}$

$\mathrm{H}_{2}$ is produced at the cathodic sites of the magnesium surface and can be oxidized at a platinum ultra-microelectrode (UME) as follows:

$H_{2} \rightarrow 2 H^{+}+2 e^{-}$(Reaction at the UME)

Thus, $\mathrm{H}_{2}$ generation can be sensed in an oxidation reaction at the UME probe potential of $0.0 \mathrm{~V}$ versus $\mathrm{Ag} / \mathrm{AgCl}$. Several researchers studied the flux of $\mathrm{H}_{2}$ gas evolving from the surface of magnesium based materials ${ }^{10,14,16-19}$.

For instance, Jamali et al. ${ }^{18}$ studied the hydrogen gas $\left(\mathrm{H}_{2}\right)$ evolution on a corroding surface of AZ31 alloy in simulated body fluid (SBF). It was found that the main domains of $\mathrm{H}_{2}$ evolution are associated with lower insulating properties of the surface as well as higher local pH. Additionally, the SECM technique was implemented for studying $\mathrm{H}_{2}$ evolution at the surface of AZ31 as a model Mg alloy. SECM results revealed that local domains of higher $\mathrm{H}_{2}$ evolution on the surface of AZ31 are in close proximity of the observed pitting sites ${ }^{10}$. 
Recently, the SECM technique was employed to map and assess the initial stages of electrochemical degradation of AZ91D Mg alloy exposed to simulated body fluid. The results indicate dynamic electrochemical activity on the AZ91D substrate at short exposure times, suggesting a rapid pit nucleation and changes in hydrogen evolution intensity ${ }^{19}$.

Therefore, for a better understanding of the degradation of magnesium alloy, different techniques are required to describe the phenomena involved in this process. In this context, scanning electrochemical microscopy (SECM) is a well-established high resolution scanning technique to monitor corrosion processes in situ. The UME is positioned close to a substrate surface for localized detection of electrochemically active species, thus producing valuable information on their local electrochemical activities ${ }^{20-23}$. This technique has been successfully applied to study magnesium alloys in different solutions $^{24}$.

The SECM technique can provide an understanding about local corrosion reactions at different exposure times of AZ31B alloy in the anodized state. Anodization is a powerful method to control the degradation rate of different metals. It consists of an electrolytic oxidation process that has been conventionally used to produce thick and stable films on metals for industrial applications, mainly aiming to increase corrosion resistance ${ }^{25,26}$. Previous studies have highlighted the use of anodizing treatments to produce protective layers on magnesium alloys ${ }^{27-29}$.

Although anodization has been the target of extensive research, the application of SECM to explore the influence of anodizing treatment in the local corrosion processes of magnesium alloys is still scarcely reported in the literature.

Thus, the aim of this work was to investigate the local corrosion processes of anodized AZ31B magnesium alloy using SECM. The measurements were made in SBF, by means of the substrate generation/tip collection (SG/TC) mode, in order to detect hydrogen evolution generated in this process.

\section{Experimental}

\subsection{Samples and solutions}

Measurements were performed on AZ31B substrates (nominal composition wt\%: Al 2.54, Zn 1.1, Mn 0.39, Mg balance).

All solutions were prepared with analytical grade reagents and ultra-pure water purified with a Milli-Q system from Millipore. All samples were abraded successively with 220 , $600,800,1200$ and 2500 grit emery paper and polished with diamond paste up to $1 \mu \mathrm{m}$. Simulated body fluid (SBF) was prepared using analytical grade reagents $(8.2 \mathrm{~g} / \mathrm{L} \mathrm{NaCl}, 1.05$ $\mathrm{g} / \mathrm{L} \mathrm{Na}_{2} \mathrm{HPO}_{4}$ and $\left.0.355 \mathrm{~g} / \mathrm{L} \mathrm{NaH}_{2} \mathrm{PO}_{4}\right)(\mathrm{pH} 7.2)$.

\subsection{Anodizing procedure}

The anodizing experiments were performed using a power supply source (Maisen MP3003D), a stainless steel container as the cathode and AZ31B magnesium alloy specimen as the anode. The sample was galvanostatically anodized in $1.0 \mathrm{M} \mathrm{NaOH}+0.5 \mathrm{M} \mathrm{Na}_{2} \mathrm{SiO}_{3}$ electrolyte at room temperature. Anodizing time was set at 5 minutes and at constant current density of $20 \mathrm{~mA} \cdot \mathrm{cm}^{-2}$.

\subsection{Scanning Electron Microscopy (SEM)}

Surface micrographs of the polished and anodized samples were obtained by SEM (Jeol JSM-6010LA).

\subsection{SECM: Instrumentation and measurements procedure}

Scanning electrochemical microscopy (SECM) was performed using a microscope built by Sensolytics $(\mathrm{GmbH}$ Bochum, Germany). An electrochemical cell was employed using $25 \mu \mathrm{m}$ Pt disk ultra-micro-electrode (UME) as working electrode, $\mathrm{Pt}$ as auxiliary-electrode and $\mathrm{Ag} / \mathrm{AgCl} / \mathrm{KCl}$ (3M) as reference electrode (Fig. 1).

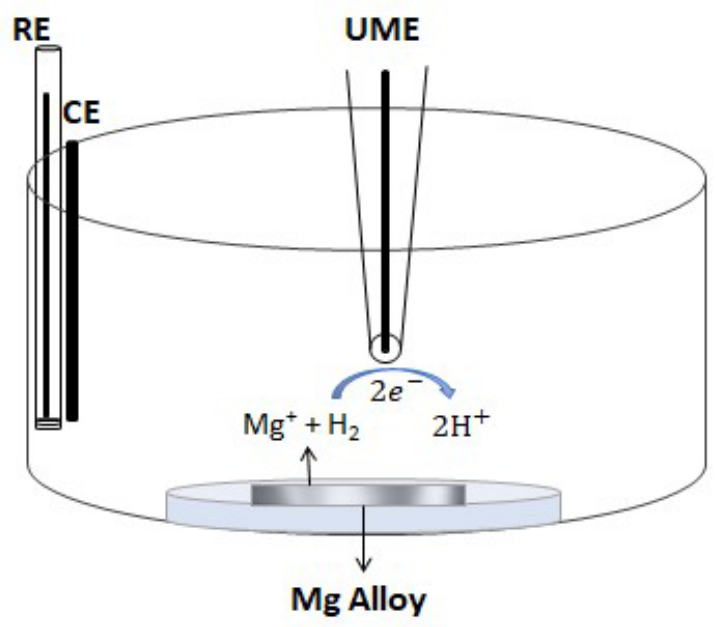

Figure 1. Schematic representation of the electrochemical cell of SECM set up in SG/TC mode.

Measurements were made at room temperature and at the open circuit potential (OCP). The AZ31B alloy was cut into strips and then embedded in epoxy resin to expose a working area of approximately $0.25 \mathrm{~cm}^{2}$. The experiments were performed at selected heights of the tip above the surface. The operati ng height was set after recording $z$ -approach curves, with the tip adjusted to $\sim 10 \mu \mathrm{m}$ above the surface. All experiments were performed using the surface generation/tip collection (SG/TC) mode. In the SG/TC mode, 
$\mathrm{H}_{2}$ generation from corrosion of magnesium alloy was sensed in an oxidation reaction at the UME probe potential of 0.0 $\mathrm{V}$ versus $\mathrm{Ag} / \mathrm{AgCl}$ (Equation 5).

\subsubsection{Cyclic voltammograms}

Cyclic voltammograms of Pt UME above AZ31B surface in the as-polished and anodized conditions at the OCP were recorded after 10 minutes of immersion in SBF solution at a scan rate of $25 \mathrm{mV} \mathrm{s}^{-1}$.

\subsubsection{SECM Z- approach curves}

Z-approach curves for a $25 \mu \mathrm{m}$ Pt UME were recorded in SBF solution at a starting distance of $100 \mu \mathrm{m}$ above the surface in the as-polished and anodized conditions at the OCP. The Z-Approach curves were acquired after 20 minutes of immersion at a scan rate of $5 \mu \mathrm{m} \mathrm{s}^{-1}$ and step site of $1 \mu \mathrm{m}$.

\subsubsection{SECM maps}

SECM maps in constant height mode were obtained by scanning the UME tip in the $\mathrm{x}-\mathrm{y}$ plane and recording the tip current as a function of its location. The maps were recorded after 30 and 80 minutes of immersion in SBF solution. A working area of $400 \mu \mathrm{m}$ x $200 \mu \mathrm{m}$ was examined in each specimen with the Pt UME biased at $0.0 \mathrm{~V}$ versus $\mathrm{Ag} / \mathrm{AgCl}$ using a scan rate of $100 \mu \mathrm{m} \mathrm{s}^{-1}$ andincrement of $25 \mu \mathrm{m}$. These parameters were used considering the high surface reactivity, where in that way each mapping was quickly obtained in approximately 5 minutes.

\section{Results and Discussion}

\subsection{Surface morphology}

SEM micrographs of the AZ31B alloy surface in the as-polished and anodized conditions are shown in Figure 2.

The morphology surface of the magnesium alloy before the exposure to SBF is shown in Figure 2a. A cellularshaped corrosion product is rapidly observed in localized areas on the surface of the freshly polished metal after 30 minutes (Fig. 2c) of immersion in SBF, as similarly found by Nordlien et al. ${ }^{30}$. Clusters of needle or flower-like crystals are developed after 80 minutes of immersion (Fig. 2e), as also observed by other authors ${ }^{31,32}$. According to the literature, these corrosion layers have the ability to slow down the dissolution process ${ }^{30-34}$. Meanwhile, the anodized layer (Fig 2b) has not been substantially affected by the SBF electrolyte during the same periods of immersion (Fig. $2 \mathrm{~d}$ and $2 \mathrm{f}$ ). In this way, the artificially grown oxide film promotes the protection of the substrate by acting as a barrier, limiting the evolution of the corrosion process.

\section{$3.2 \mathrm{H}_{2}$ generation studied in substrate generation/Tip collection mode}

\subsubsection{Cyclic voltammograms}

Initially, cyclic voltammograms of the AZ31B magnesium alloy in the as-polished and anodized conditions were recorded in SBF using the $25 \mu \mathrm{m} \mathrm{UME} \mathrm{(Fig.} \mathrm{3).}$

When the UME was positioned at $10 \mu \mathrm{m}$ above the surface of the as-polished magnesium alloy, an oxidation current around $900 \mathrm{nA}$ was observed at height of the peak, which is attributed to the oxidation of hydrogen $\left(\mathrm{H}_{2}\right)$ generated on its surface. However, when the UME was positioned in the same distance above the anodized magnesium alloy the current value was greatly reduced, which is associated to the local protection effect provided by the anodized layer. No oxidation peak was observed and the current was substantially reduced when the UME was positioned at longer distances from the surfaces.

\subsubsection{SECM Z- approach curves}

Figure 4 shows the Z-approach curves for a $25 \mu \mathrm{m} \mathrm{Pt}$ UME recorded in SBF solution at a starting distance of 100 $\mu \mathrm{m}$ above the surface.

Near to the magnesium alloy surface, $\mathrm{H}_{2}$ evolution was significantly reduced for the anodized AZ31B alloy. It is clearly observed that there is a lower $\mathrm{H}_{2}$ current evolution in Figure 4b compared to Figure 4a. Moreover, in Figure 4a an increase in current can be perceived, which is related to intense gas generation from the AZ31B Mg surface in the as-polished condition. The anodizing process dramatically decreases the current near the surface of AZ31B Mg alloy.

\subsubsection{SECM maps}

The SG/TC SECM mode was also applied to map hydrogen released from the $\mathrm{AZ31B} \mathrm{Mg}$ alloy surface in the as-polished and anodized conditions when immersed in SBF solution. The maps were recorded 30 and 80 minutes of immersion (Fig.5).

In Figure 5, the upper and lower color scales are an indicative of different current intensities for hydrogen evolution in the AZ31B Mg alloy surface in the as-polished and anodized conditions. The upperscale colors (red and yellow) indicate the areas with high $\mathrm{H}_{2}$ evolution rate whereas the lower scale colors (blue and green) represent the relatively passive areas with incipient $\mathrm{H}_{2}$ formation.

After 30 minutes of immersion the current response was significantly higher in the AZ31B Mg alloy surface in the as-polished condition (Fig. 5a). The same behavior was observed after 80 minutes of immersion. However, the current 


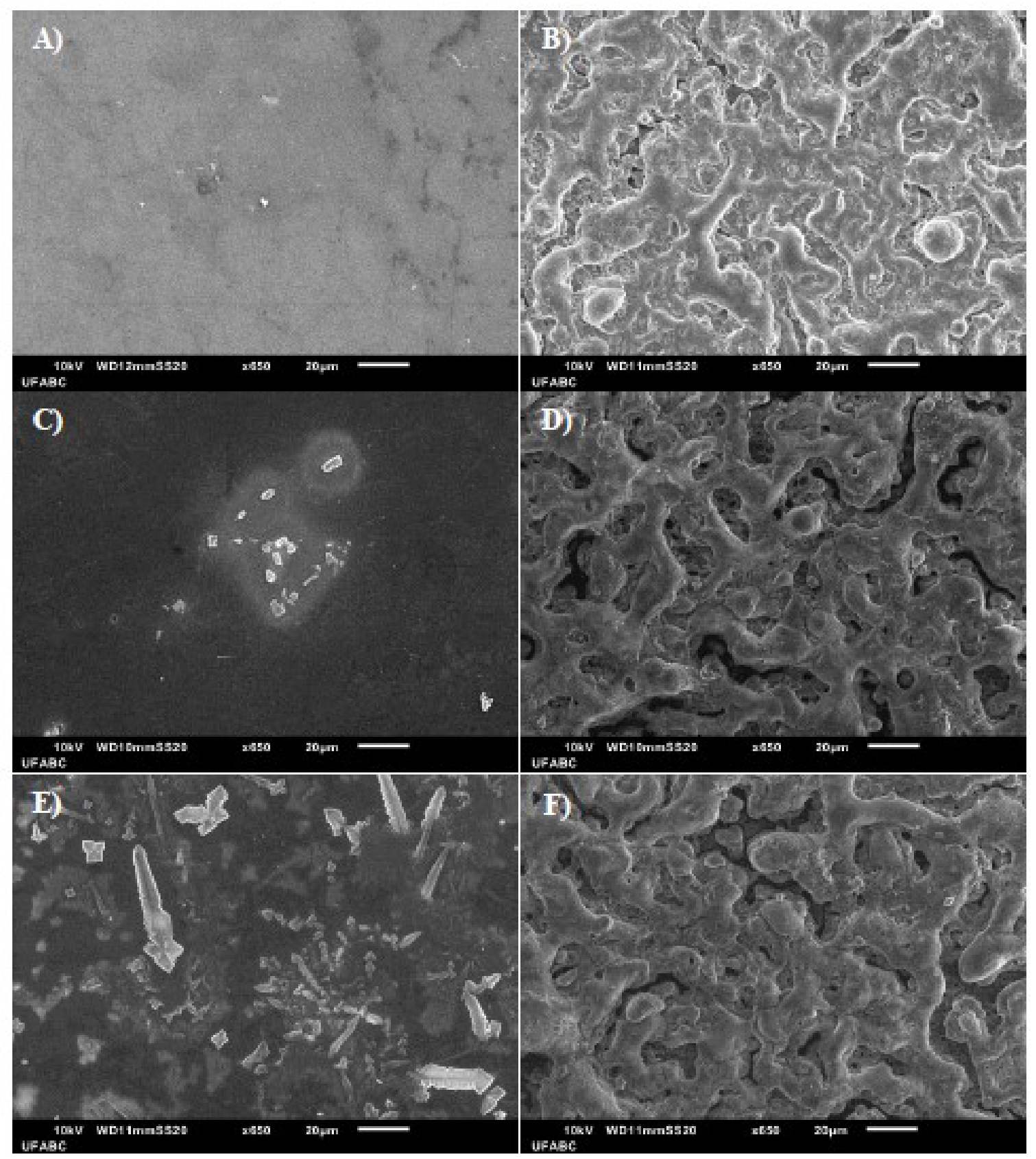

Figure 2. SEM images of AZ31B alloy surface: a) as-polished; b) anodized film; c) as-polished after 30 min; d) anodized film after 30 $\mathrm{min}$; e) as-polished after $80 \mathrm{~min}$; f) anodized after $80 \mathrm{~min}$ immersed into SBF.

values measured at 30 and 80 minutes indicate that hydrogen evolution is higher at the beginning of the experiments and decreases over time. This behavior may be attributed to the early formation of a magnesium oxi-hydroxide film over the surface exposed to SBF (Fig. 2c and 2e). The formation of a magnesium oxi-hydroxide film over magnesium alloys surface has been reported ${ }^{19,35-38}$.
For instance, the SG/TC SECM mode was applied by Mena-Morcillo et al. ${ }^{19}$ to map the hydrogen released from AZ91D magnesium alloy surface at short periods of immersion in simulated body fluid. The current values measured at $10 \mathrm{~min}, 1 \mathrm{~h}$, and $2 \mathrm{~h}$ indicated that hydrogen evolution was higher at the beginning of the experiments, diminishing over time due to the possible early formation of corrosion products ${ }^{19}$. 


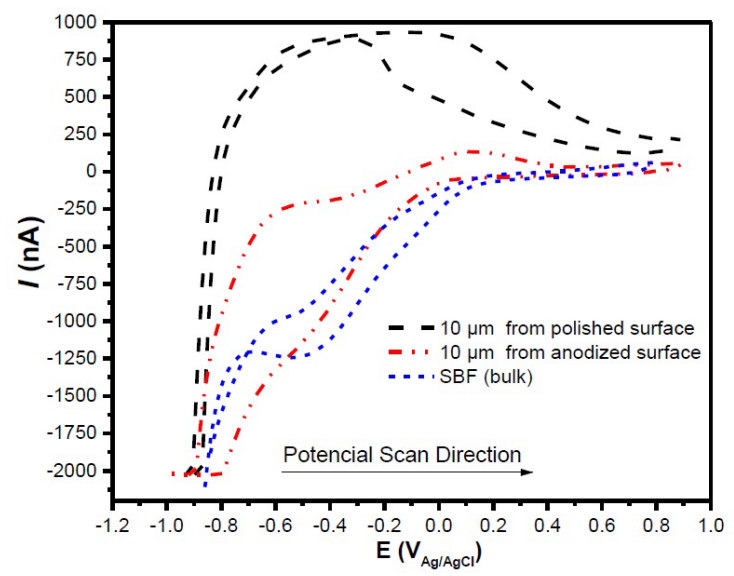

Figure 3. Cyclic voltammograms of Pt UME above AZ31B surface at the OCP after 10 minutes of immersion in SBF solution at a scan rate of $25 \mathrm{mV} \mathrm{s}^{-1}$.
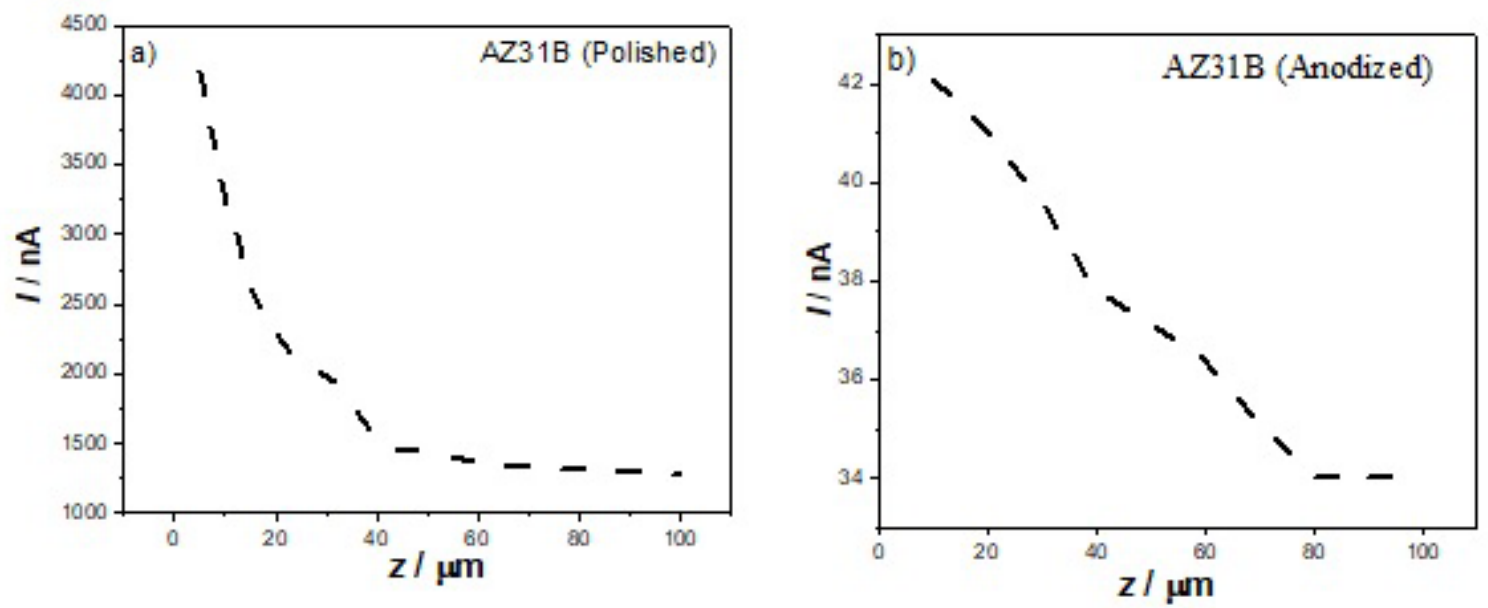

Figure 4. Z-Approach curves for a $25 \mu \mathrm{m}$ Pt UME biased at $0.0 \mathrm{~V}$ on the AZ31B alloy at the OCP: polished (a) and anodized (b) conditions in SBF solution. The Z-Approach curves were acquired after 20 minutes of immersion at a scan rate of $5 \mu \mathrm{m} \mathrm{s}^{-1}$.

Here, this effect was more evident in the AZ31B Mg alloy surface in the as-polished condition. For the anodized surface, after 80 minutes, no significant variation of current values was observed (Fig. 5d). This behavior may be attributed to the protection ability of the anodized layer that hinders the local corrosion reactions and, consequently, decreases hydrogen generation.

SECM proved to be an effective tool to assess the protective ability of the anodized layer formed on the AZ31B alloy. By sensing the hydrogen evolution reaction at the specimen's surface local corrosion processes could be successively mapped using the SG/TC mode. Up to the author's knowledge the successful use of SECM to examine local corrosion spots of anodized magnesium surfaces is reported for the first time in the current literature. It opens an extensive research frontier for examining the effectiveness of anodized layers in protecting magnesium alloys from corrosion over time, correlating anodizing parameters, surface defects and local corrosion spots. This research is currently ongoing by our group and will be published in a near future. 

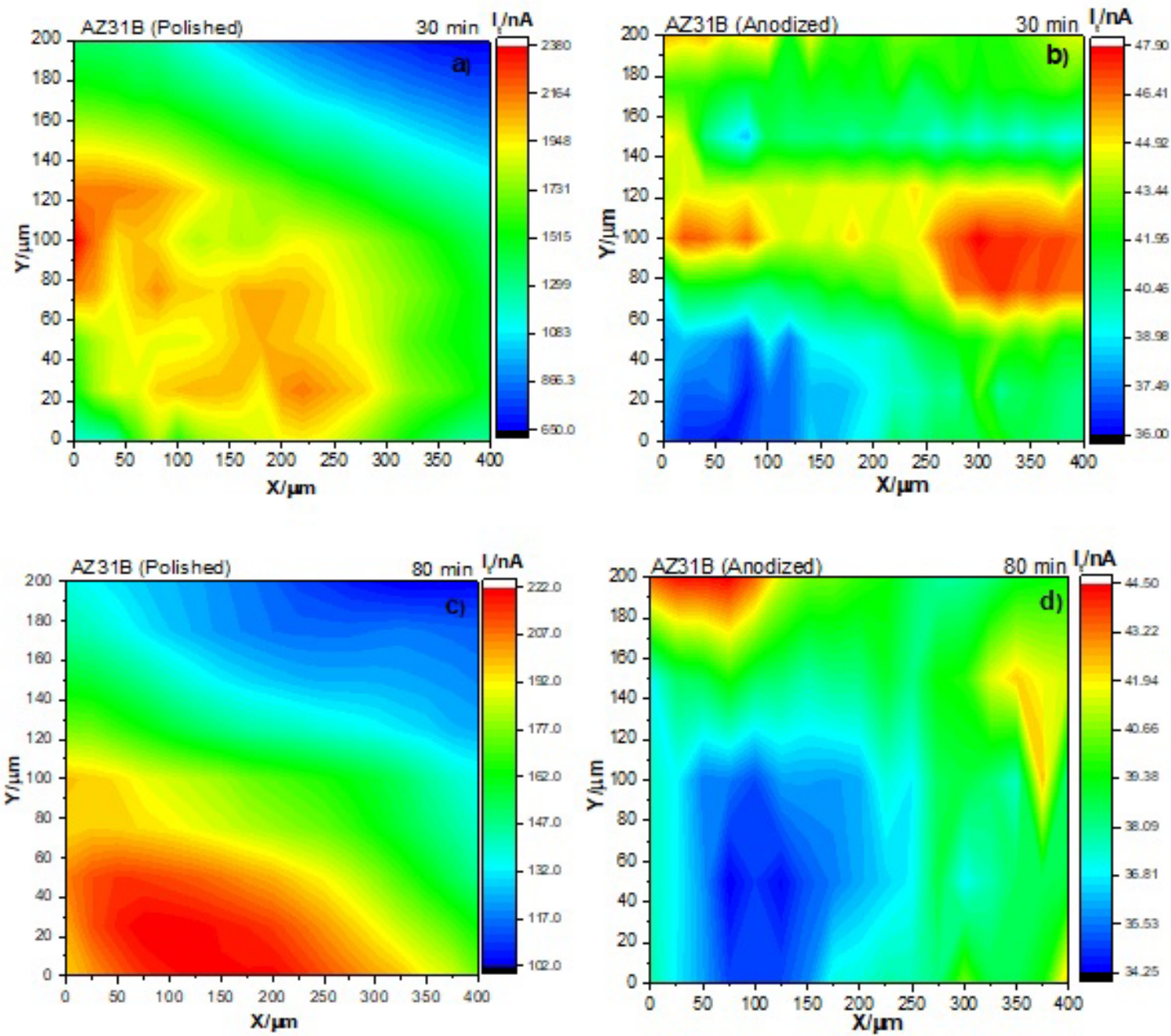

Figure 5. Hydrogen evolution (HE) maps of AZ31B alloy immersed in SBF. HE maps were acquired by SG/TC mode of SECM using a $25 \mu \mathrm{m}$ Pt UME biased at $0.0 \mathrm{~V}$ versus $\mathrm{Ag} / \mathrm{AgCl}$. The SECM maps of AZ31B surface were acquired at the open circuit potential after 30 minutes of immersion for the as-polished (a) and anodized conditions (b), and after 80 minutes of immersion for the as-polished (c) and anodized conditions (d).

\section{Conclusions}

The present study demonstrates that SECM in the SG/ TC mode is an ideal tool to investigate the difference in spontaneous corrosion activity of anodized and polished AZ31B Mg alloy at short periods of immersion in simulated body fluid. The different SECM measurements showed that a higher $\mathrm{H}_{2}$ evolution flux, sensed in an electro-oxidation reaction at the SECM probe, produced a significantly higher current in the polished AZ31B alloy surface when compared to the anodized alloy. It was found that the anodizing process decreases the hydrogen evolution on the surface, and consequently, the current obtained near the surface dramatically decreases. Hydrogen evolution (HE) maps indicated a higher $\mathrm{H}_{2}$ generation at the beginning of the experiments and lower generation over time, associated with the early formation of a film of corrosion products. This effect was more evident in the AZ31B Mg alloy surface in the as-polished condition. For the anodized surface, no significant variation of current values was observed, indicating a protective effect that decreases the local corrosion reactions.

\section{Acknowledgements}

The authors thank the Brazilian agencies FAPESP (Proc. 2015/22921-6) and CAPES (Finance code 001) for the financial support, and the Multiuser Experimental Facilities (UFABC) for the experimental support for this work. 


\section{References}

1. Erbel R, Di Mario C, Bartunek J, Bonnier J, Bruyne B, Eberli FR, et al. Temporary scaffolding of coronary arteries with bioabsorbable magnesium stents: a prospective, non-randomised multicentre trial. Lancet. 2007;369(9576):1869-75.

2. Esmaily M, Svensson JE, Fajardo S, Birbilis N, Frankel GS, Virtanen S, et al. Fundamentals and advances in magnesium alloy corrosion. Progress in Materials Science. 2017;89:92-193.

3. Mueller WD, Nascimento ML, Mele MFL. Critical discussion of the results from different corrosion studies of $\mathrm{Mg}$ and $\mathrm{Mg}$ alloys for biomaterial applications. Acta Biomaterialia. 2010;6(5):1749-55.

4. Staiger MP, Pietak AM, Huadmai J, Dias G. Magnesium and its alloys as orthopedic biomaterials: A review. Biomaterials. 2006;27(9):1728-34.

5. Virtanen S. Biodegradable Mg and Mg alloys: Corrosion and biocompatibility. Materials Science and Engineering: $B$. 2011;176(20):1600-8.

6. Witte F, Hort N, Vogt C, Cohen S, Kainer KU, Willumeit R, et al. Degradable biomaterials based on magnesium corrosion. Current Opinion in Solid State and Materials Science. 2008;12(56):63-72.

7. Xin Y, Hu T, Chu PK. In vitro studies of biomedical magnesium alloys in a simulated physiological environment: A review. Acta Biomaterialia. 2011;7(4):1452-9.

8. Ding HL, Hirai K, Homma T, Kamado S. Numerical simulation for microstructure evolution in AM50 Mg alloy during hot rolling. Computational Materials Science. 2010;47(4):919-25.

9. Pardo A, Merino MC, Coy AE, Viejo F, Arrabal R, Feliú S. Influence of microstructure and composition on the corrosion behaviour of $\mathrm{Mg} / \mathrm{Al}$ alloys in chloride media. Electrochimica Acta. 2008;53(27):7890-902.

10. Jamali SS, Moulton SE, Tallman DE, Forsyth M, Weber J, Wallace GG. Evaluating the corrosion behaviour of Magnesium alloy in simulated biological fluid by using SECM to detect hydrogen evolution. Electrochimica Acta. 2015;152:294-301.

11. Song G. Recent Progress in Corrosion and Protection of Magnesium Alloys. Advanced Engineering Materials. 2005;7(7):563-86.

12. Song G. Control of biodegradation of biocompatable magnesium alloys. Corrosion Science. 2007;49(4):1696-701.

13. Song G, Atrens A. Understanding Magnesium Corrosion-A Framework for Improved Alloy Performance. Advanced Engineering Materials. 2003;5(12):837-58.

14. Tefashe UM, Snowden ME, Ducharme PD, Danaie M, Botton GA, Mauzeroll J. Local flux of hydrogen from magnesium alloy corrosion investigated by scanning electrochemical microscopy. Journal of Electroanalytical Chemistry. 2014;720-721:121-7.

15. Song G, Atrens A. Recent Insights into the Mechanism of Magnesium Corrosion and Research Suggestions. Advanced Engineering Materials. 2007;9(3):177-83.
16. Dauphin-Ducharme P, Asmussen RM, Tefashe UM, Danaie M, Binns WJ, Jakupi P, et al. Local Hydrogen Fluxes Correlated to Microstructural Features of a Corroding Sand Cast AM50 Magnesium Alloy. Journal of the Electrochemical Society. 2014;161(12):C557-C64.

17. Izquierdo J, Fernández-Pérez BM, Filotás D, Ori Z, Kiss A, Martín-Gómez RT, et al. Imaging of Concentration Distributions and Hydrogen Evolution on Corroding Magnesium Exposed to Aqueous Environments Using Scanning Electrochemical Microscopy. Electroanalysis. 2016;28(10):2354-66.

18. Jamali SS, Moulton SE, Tallman DE, Forsyth M, Weber J, Wallace GG. Applications of scanning electrochemical microscopy (SECM) for local characterization of AZ31 surface during corrosion in a buffered media. Corrosion Science. 2014;86:93100.

19. Mena-Morcillo E, Veleva L, Wipf DO. In situ Investigation of the Initial Stages of AZ91D Magnesium Alloy Biodegradation in Simulated Body Fluid. International Journal of Electrochemical Science. 2018;13:5141-50.

20. Bard AJ, Fan FRF, Mirkin MV. Scanning electrochemical microscopy. In: Bard AJ, editor. Electroanalytical chemistry. New York: Marcel Dekker; 1994. p. 243-373. v. 18.

21. González-García Y, Santana JJ, González-Guzmán J, Izquierdo J, González S, Souto RM. Scanning electrochemical microscopy for the investigation of localized degradation processes in coated metals. Progress in Organic Coatings. 2010;69(2):110-7.

22. Martin AE, Sophie M, Anna LW, Julie VM, Patrick RU. Scanning electrochemical microscopy: principles and applications to biophysical systems. Physiological Measurement. 2006;27(12):R63-R108.

23. Santana JJ, González-Garcia S, Izquierdo J, Souto RM. Applications of scanning electrochemical microscopy (SECM) for the investigation of local corrosion processes. Afinidad (Barcelona). 2011;68:44-9.

24. Thomas S, Izquierdo J, Birbilis N, Souto RM. Possibilities and Limitations of Scanning Electrochemical Microscopy of $\mathrm{Mg}$ and Mg Alloys. Corrosion (Houston). 2015;71(2):171-83.

25. Blawert C, Dietzel W, Ghali E, Song G. Anodizing Treatments for Magnesium Alloys and Their Effect on Corrosion Resistance in Various Environments. Advanced Engineering Materials. 2006;8(6):511-33.

26. Bonilla FA, Berkani A, Skeldon P, Thompson GE, Habazaki H, Shimizu K, et al. Enrichment of alloying elements in anodized magnesium alloys. Corrosion Science. 2002;44(9):1941-8.

27. Hiromoto S, Yamamoto A. Control of degradation rate of bioabsorbable magnesium by anodization and steam treatment. Materials Science and Engineering: C. 2010;30(8):1085-93.

28. Santamaria M, Di Quarto F, Zanna S, Marcus P. The influence of surface treatment on the anodizing of magnesium in alkaline solution. Electrochimica Acta. 2011;56(28):10533-42. 
29. Ximei W, Liqun Z, Huicong L, Weiping L. Influence of surface pretreatment on the anodizing film of $\mathrm{Mg}$ alloy and the mechanism of the ultrasound during the pretreatment. Surface and Coatings Technology. 2008;202(17):4210-7.

30. Nordlien JH, Ono S, Masuko N, Nisancioglu K. Morphology and Structure of Oxide Films Formed on Magnesium by Exposure to Air and Water. Journal of the Electrochemical Society. 1995;142(10):3320-2.

31. Feliu Junior S, Llorente I. Corrosion product layers on magnesium alloys AZ31 and AZ61: Surface chemistry and protective ability. Applied Surface Science. 2015;347(30):736-46.

32. Esmaily M, Mortazavi N, Shahabi-Navid M, Svensson JE, Johansson LG, Halvarsson M. On the capability of in-situ exposure in an environmental scanning electron microscope for investigating the atmospheric corrosion of magnesium. Ultramicroscopy. 2015;153:45-54.

33. Pardo A, Merino MC, Coy AE, Arrabal R, Viejo F, Matykina E. Corrosion behaviour of magnesium/aluminium alloys in 3.5wt.\% NaCl. Corrosion Science. 2008;50(3):823-34.
34. Xin Y, Huo K, Tao H, Tang G, Chu PK. Influence of aggressive ions on the degradation behavior of biomedical magnesium alloy in physiological environment. Acta Biomaterialia. 2008;4(6):2008-15.

35. Heakal F, Fekry AM, Fatayerji MZ. Electrochemical behavior of AZ91D magnesium alloy in phosphate medium-part I. Effect of pH. Journal of Applied Electrochemistry. 2009;39(5):583-91.

36. Gopi D, Bhalaji PR, Ramya S, Kavitha L. Evaluation of biodegradability of surface treated AZ91 magnesium alloy in SBF solution. Journal of Industrial and Engineering Chemistry. 2015;23:218-27.

37. Heakal F, Fekry AM, Fatayerji MZ. Electrochemical behavior of AZ91D magnesium alloy in phosphate medium: Part II. Induced passivation. Journal of Applied Electrochemistry. 2009;39(9):1633-42.

38. Xin Y, Liu C, Zhang X, Tang G, Tian X, Chu PK. Corrosion behavior of biomedical AZ91 magnesium alloy in simulated body fluids. Journal of Materials Research . 2007;22(7):200411 . 